\title{
Evaluation of Apoptotic proteins (p53 and Bcl-2) expression in trophoblastic tissue of women infected with Toxoplasma gondii diagnosed by polymerase chain reaction
}

Nidhal, Abdulmohaimen and Safaa, Mezban

Al-Nahrain college of medicine/Dept. microbiology

correspoder auther, e-mail:dr.nidhalmohammed@yahoo.com

\begin{abstract}
Background: Gene amplification methods (PCR, LCR, NASBA, etc.) are now used widely in the diagnosis of infectious diseases. Certain types of oncogene products, are known to be physiologically expressed in the placenta among these products are Bcl-2 and p53 proteins.

Aim: Use of gene amplification (Polymerase Chain Reaction/ PCR) in the investigation and diagnosis of toxoplasmosis .And to evaluate Bcl-2 and p53 as an anti-apoptotic and pro-apoptotic proteins in the trophoblastic tissue of T.gondii positive, negative and induced aborted women.

Materials and methods: A total of forty pregnant women, their age ranged from $(20-50)$ years, were enrolled in the current study and were further classified into three categories: Toxoplasma gondii positive patients: with spontaneous miscarriage (20 women), Toxoplasma gondii negative patients: with spontaneous miscarriage (10 women) and control group (women with induced abortion for medical causes) (10 women).

Venous blood was collected from all women, for the detection of specific antiToxoplasma gondii IgM in the serum using the ELISA test. polymerase chain reaction technique (PCR) was used for the detection of Toxoplasma gondii DNA in trophoplastic tissue as a diagnostic methods for T.gondii for both positive and negative groups,and for immunohistochemical analysis for the detection of apoptotic proteins (Bcl-2 and p53).
\end{abstract}

Results: Twelve (40\%) samples out of the (30) were negative for antiToxoplasma gondii IgM while the rest 18 (60\%) were positive for IgM, but when using polymerase chain reaction (PCR) two of the negative samples in ELISA were found to be positive for toxoplasma B1 specific gene. The highest percentage of Bcl-2 was found in the T.gondii negative group (34.90\% \pm 3.44$)$ and control group (38.19\% \pm 0.79 , while the lowest percentage $(10.93 \% \pm 1.44)$ was found in the T.gondii positive group.

There was no statistical difference $(\mathrm{p} \leq 0.363)$ in the mean percentage of Bcl-2 between $T$. gondii negative and control group; while there was a high significant differences $(\mathrm{p}=0.000)$ in the mean percentage of $\mathrm{Bcl}-2$ in $T$. gondii positive group compared to cotrols. In addition a high significant differences $(p=0.000)$ in the mean percentage of Bcl-2 was found between T. gondii positive and negative groups.

The highest percentage of expression of $\mathrm{p} 53$ protein was found in the T.gondii positive group $(31.56 \% \pm 1.28)$ and the lowest percentage was in both T.gondii negative and control groups ( $18.93 \pm 1.054$ and $11.73 \pm 1.810$ respectively).

There was statistical difference $(\mathrm{p} \leq 0.003)$ in the mean percentage of $\mathrm{p} 53$ between T.gondii negative and control groups .In addition there was high significant differences $(\mathrm{p}=0.000)$ in the mean percentage of $\mathrm{p} 53$ between T.gondii positive group and control groups and between T.gondii positive and negative groups.

Conclusiocn: This assures the specificity and sensitivity of polymerase chain reaction as a molecular method for diagnosis of: Toxoplasma gondii. And high levels 
of p53 protein found in positive samples for toxoplasma gondii infection might indicated the important role of this protein in cell death and induction of apoptosis that lead to the end of pregnancy with abortion. Low levels of Bcl-2 in aborted women infected with T.gondii might indicated that $\mathrm{Bcl}-2$ have no role in preventing or initiate apoptosis.

\section{INTRODUCTION}

Toxoplasma gondii is one of the most widespread parasites that infects a large proportion of the world's population, and causes an infectious disease called toxoplasmosis, which can cause a wide range of clinical syndromes in humans. Although most individuals do not experience any symptoms, the disease can be very serious, severe or life-threatening and even fatal in certain individuals including fetuses, newborns, pregnant women and individuals with a weakened immune system (Hökelek, 2005). In addition, it has been established that Toxoplasma gondii can be transmitted from a recently infected mother to her fetus. During pregnancy the primary infection may lead to severe if not fatal complications for the fetus. These direct effects can lead to spontaneous miscarriage, stillbirth or congenital anomalies (Remington, 2001; Fatoohi et al., 2002; Nazan Dalgic, 2008). In this regard, the proportion of women at risk of acquiring the infection during pregnancy in many countries, including Iraq, is not well known; therefore, emphasis has been placed on preventive measures and early diagnosis of the infection to prevent these severe complications (Nimri et al., 2004). Currently, serological testing has been one of the major diagnostic techniques for toxoplasmosis, in Iraq, and although it appears to be a reliable, rapid and sensitive assay for detecting Toxoplasma antibodies, it is still complicated and time-consuming and has many limitations ( Pashanina et al., 2005; Pelloux et al., 2006).

An alternative method of identifying Toxoplasma gondii can be used to establish a diagnosis and confirm the infection by parasites when serological tests are not definitive. PCR assays have been developed and widely used in the detection of Toxoplasma gondii DNA, in which primers specific to different regions of the genome of the parasite have been used. The method can be applied to amniotic fluid, vitreous fluid, cerebrospinal fluid, blood samples and tissue specimens (Matos et al., 2007). Their advantages are relative speed, the potential to detect very low numbers of pathogens (or, more precisely, specific nucleic acid sequences from pathogens) and the ability to discriminate accurately at the species or sub-species level (Alfonso $e t$ al., 2008).

The human placenta is an important organ for the maintenance of pregnancy, and comprises both functional and mechanical interphase between the mother and the fetus. From the initiation of pregnancy, the placenta itself grows and matures until the end of pregnancy. As gestation progresses, the villi and lining trophoblast show evidence of maturation and differentiation, and the rate of placental growth is known to decline gradually after 34 to 36 weeks of gestation. Considering that programmed cell death (PCD) or apoptosis is one of the critical processes during fetal development. It is plausible that the process may play a significant role in placental development and maturation with the evolution of pregnancy, and also may be related to placental aging and complicated pregnancy. Various kinds of significant substances, including certain types of oncogene products, are known to be physiologically expressed in the placenta among these products are $\mathrm{Bcl}-2$ and $\mathrm{p} 53$ proteins (yong-beom kim et al 2001).

Apoptosis is described in normal villous trophoblast and elements of the apoptotic machinery are involved in the fusion between cytotrophoblast and the overlying multinucleate syncytiotrophoblast. It is anticipated that understanding the regulation of apoptosis in villous trophoblast may provide new insights into placental pathologies. 


\section{MATERIALS AND METHODS}

Thirty pregnant women with spontaneous miscarriage who had curettage operation at the Obstetrics and Gynecology Department of Al-Yarmouk Teaching Hospital in Baghdad between December 2006 and March 2007 were subjected to this study. Their age ranged from 20-50 years.

To exclude other causes of miscarriage, the sera of patients were examined against syphilis, Rubella, Cytomegalovirus and Herpes simplex virus. None of the patients were diabetic or had symptoms of hypertension. .ELISA test was used for the detection of specific T.gondii $\operatorname{IgM}$, in the serum of the patients, and paraffin-embedded trophoplastic tissues from the same patients were provided to confirm the infection with T.gondii using Polymerase chain reaction (PCR).

Twenty (20) aborted women were positive for T.gondii infection, and the other ten (10) aborted women were negative for infection. Ten(10) other women who were admitted to al-khadymia teaching hospital for elective termination of pregnancy (induced abortion) due to maternal cardiac disease were underwent the study as a control group.

A trophoblastic tissue placenta sample from each curettage patient and control subject was collected and placed in $10 \%$ formaldehyde. Two to three paraffin embedded blocks were prepared for each patient (World Health Organization, 2003).

Five $\mathrm{ml}$ of venous blood were collected from each subject. The blood was placed in a plain tube and left to stand for 30 minutes at room temperature to clot. Then, the tube was centrifuged at $300 \mathrm{XG}$ for 10 minutes to collect the serum, which was frozen at $-20^{\circ} \mathrm{C}$ after dividing into aliquots $(0.5 \mathrm{ml})$.

Enzyme Linked Immunosorbent Assay for the detection of IgM antibodies for Toxoplasma gondii in serum

This assay was performed using commercial kits (Biokit Diagnostics Company, Spain) for the detection of IgM anti-Toxoplasma gondii antibodies in serum.

\section{Polymerase chain reaction (PCR)}

DNA extracted from paraffin embedded tissue blocks by Organic (Phenolic) extraction method (National Institute of Health, 2004)].

Five microlitters of $T$. gondii DNA was used for amplification of B1 gene. Resolution of a band about 160 bp in size was regarded to be positive.

The sequences of the primers used were: 1- 5' A A A A G A G G A A G A G A C G C TGCCGCTG -3' (position 572 to 596, primer 3)2- 5'-G C C A T T T T C T G A G C A TCCCTTCCG-3' (position 1137 to 1160 , primer 4)

3-5'-GGAACTGCATCCGTTCATGAG-

3' (position 694 to 714, primer T1) 4- 5'-G GCGACCAATCTGCGAATACACC-3'

position 853 to 831 , primer T Oligo). PCR products were analyzed by electrophoresis on an agarose gel and photographed under an ultraviolet transluminator. PCR product sizes were compared with a PBR322-HinfI size marker (Pharmacia Biotech) and products with the exact same size, as those in the positive controls (about 160-base pairs), were regarded positive for $\mathrm{T}$. gondii(Assmar et al.2000).

\section{Immunohistochemical detection of $p 53$ and $\mathrm{Bcl}-2$}

Monoclonal Mouse Anti p53 and $\mathrm{Bcl}-2$ (DakoCytomation) were used.And the procedure were done according to the manufuturer instructions. The expression of p53 and $\mathrm{Bcl}-2$ proteins were measured by counting the number of the positive cells with brown (DAB) nuclear staining in one microscopic field under light microscopy (X400) and then divided by the total cells on the same field multiply by 100 as explained in the equation below: P53 or $\mathrm{Bcl}-2(\%)=$ number of cells positive for p53in one field / total Cells (positive and negative) in the same field X 100 .

\section{Statistical Analysis}

The data processing was done by using Statistical Package of Social Science (SPSS) version 16. Data description was presented as means with their standard errors (SE) and standard deviation (SD) were calculated to reflect the size and precision of the estimated values.

The independent sample t-test of significance was used for the comparison between two groups .the lowest level of 
significance chosen to be when the probability ( $p$ ) was less than or equal to $0.05(\mathrm{p} \leq 0.05)$.

\section{RESULTS}

Regarding the patients group (spontaneous aborted women) 18 (60\%) out of the (30) blood samples were positive for anti-Toxoplasma gondii IgM and the rest $12(40 \%)$ were negative for $\operatorname{IgM}$.

In addition to the ELISA results, trophoblastic tissues of spontaneous aborted women who were found either positive or negative for Toxoplasma gondii infection where further used to confirm the presence or absence of Toxoplasma gondii B1 gene using the polymerase chain reaction technique. Twenty samples (66.6\%) where positive for B1 gene (equal to $160 \mathrm{bp}$ ) and 10 samples (33.3\%) where negative for B1 gene (less than $160 \mathrm{bp}$ ) as shown in Fig.1.

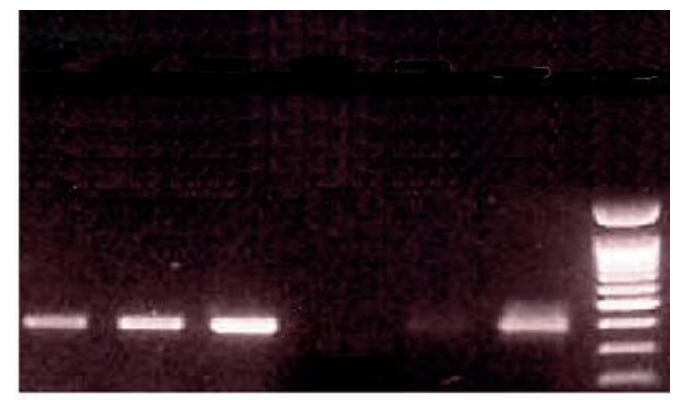

Fig. 1: PCR results of trophoblastic tissue samples from $T$. gondii infected patients for both positive and negative groups. Lines 1, 2, 3 positive specimens; 4, negative specimen; 5, negative control; 6 , positive control and 7 , marker.

Fig. 2, and table-1 show that there were highly significant decrease in mean percentage of Bcl-2 in Toxoplasma gondii positive group (10.93\%) compared to induced abortion group $(38.19 \%)(\mathrm{P}<0.001)$. A high mean percentage of Bcl-2 protein was found also in Toxoplasma gondii negative group (34.9\%).

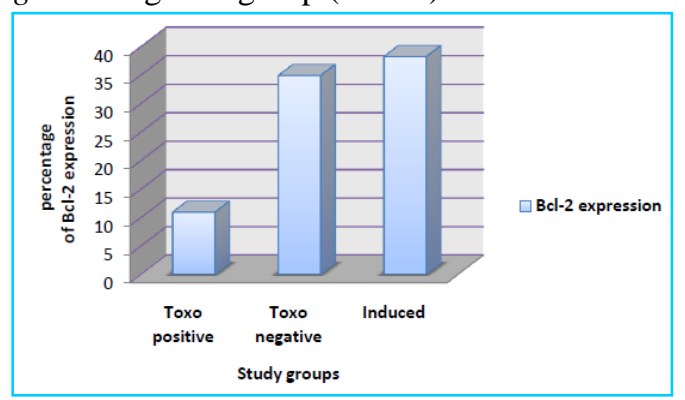

Fig. 2: the expression of Bcl-2 among the three groups
Table1: Bcl-2 expression among the study groups.

\begin{tabular}{|c|c|c|c|c|c|c|c|c||}
\hline Marker & Group & No. & $\begin{array}{c}\text { Mean } \\
(\%)\end{array}$ & SE & SD & P1 & P2 & P3 \\
\hline \multirow{2}{*}{$\begin{array}{c}\text { Bcl-2 } \\
\text { expression }\end{array}$} & $\begin{array}{c}\text { Toxo } \\
\text { positive }\end{array}$ & 20 & 10.93 & 1.442 & 6.447 & & & \\
\cline { 2 - 6 } & $\begin{array}{c}\text { Toxo } \\
\text { negative }\end{array}$ & 10 & 34.90 & 3.445 & 10.893 & $\begin{array}{c}0.000 \\
\text { (HS) }\end{array}$ & $\begin{array}{c}0.363 \\
(\text { NS) }\end{array}$ & $\begin{array}{c}0.000 \\
\text { (HS) }\end{array}$ \\
\cline { 2 - 6 } & $\begin{array}{c}\text { Induced } \\
\text { abortion }\end{array}$ & 10 & 38.19 & 0.791 & 2.501 & & & \\
\\
HS=Highly significant NS=Not significant
\end{tabular}

$\mathrm{P} 1=$ toxoplasma positive group vs. induced group $\mathrm{P}<0.00$ (HS)

$\mathrm{P} 2=$ toxoplasma negative group vs. induced group $\mathrm{P} \leq 0.363$ (NS)

$\mathrm{P} 3=$ toxoplasma positive group vs. negative group $\mathrm{P} \leq 0.001$ (HS)

These differences was highly significant $(\mathrm{P}<0.001)$ as compared with the Toxoplasma gondii positive group, but failed to reach a significant level $(\mathrm{P} \leq 0.363)$ after comparing with induced abortion (control group).

Fig. 3, and table 2 show that there were highly significant increase in mean percentage of $\mathrm{p} 53$ in Toxoplasma gondii positive group $(31.56 \%) \quad(\mathrm{P}<0.001)$ compared to Toxoplasma gondii negative group (18.93\%) and induced abortion group (11.73\%).

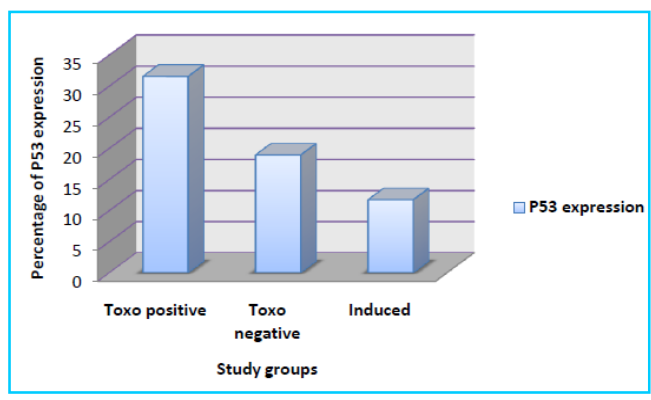

Fig. 3: the expression of p53 protein among the three groups.

Table 2: p53 expression among the study groups.

\begin{tabular}{||c|c|c|c|c|c|c|c|c|}
\hline Marker & Grouping & No. & Mean & SE & SD & P1 & P2 & P3 \\
\hline \multirow{2}{*}{$\begin{array}{c}\text { p53 } \\
\text { expression }\end{array}$} & $\begin{array}{c}\text { Toxo } \\
\text { positive }\end{array}$ & 20 & 31.56 & 1.285 & 5.749 & & & \\
\cline { 2 - 6 } & $\begin{array}{c}\text { Toxo } \\
\text { negative }\end{array}$ & 10 & 18.93 & 1.054 & 3.333 & $\begin{array}{c}0.000 \\
\text { (HS) }\end{array}$ & $\begin{array}{c}0.003 \\
\text { (S) }\end{array}$ & $\begin{array}{c}0.000 \\
\text { (HS) }\end{array}$ \\
\cline { 2 - 6 } & Induced & 10 & 11.73 & 1.810 & 5.723 & & & \\
\hline
\end{tabular}

HS= Highly significant $\mathrm{S}=$ Significant

$\mathrm{P} 1=$ toxoplasma positive group vs. induced group $\mathrm{P}<0.000$ (HS)

$\mathrm{P} 2=$ toxoplasma negative group vs. induced group $\mathrm{P} \leq 0.003$ (S) $\mathrm{P} 3=$ toxoplasma positive group vs. negative group $\mathrm{P} \leq 0.001$ (HS 
These differences was highly significant $(\mathrm{P}<0.001)$ as compared with the Toxoplasma gondii negative, and induced abortion groups. Figs. 4 and 5 show the results of immunohistochemistry for both proteins in trophoplastic tissues.

\section{DISCUSSION}

Congenital toxoplasmosis results from foetus contamination by Toxoplasma gondii during pregnancy. It is a frequent and severe condition calling for close monitoring of mothers at risk. During the last decades, numerous advances have been made specially in the antenatal diagnosis. The congenital toxoplasmosis diagnosis relies currently on PCR test of amniotic fluid, with a sensitivity of $80 \%$ (ordinarie). We therefore compared the diagnosis value of conventional PCRhybridization for the diagnosis of congenital toxoplasmosis with the traditional method (serology) used in Iraqi hospitals for the determination of IgM anti Toxoplasma gondii antibodies.

The results of the present study showed that the polymerase chain reaction (PCR) is highly sophisticated tool for diagnosis of $\mathrm{B} 1$ Toxoplasma gondii specific gene that most researches depend on, and the detection for this gene showed differences between the serological and molecular method for detection(dupon et al.,1995). Two out of the $12(40 \%)$ negative samples, that was diagnosed by (ELISA) test was approved positive samples by PCR and this indicate, the specificity and sensitivity of the molecular diagnostic method that we used and these results were in agreement with (Fabio et $a l$. , 2005) in that the importance of molecular and immunological methods in the diagnosis of Toxoplasma gondii. And that, we can account on PCR to confirm that suspected pregnant patients were having toxoplasmosis or not because diagnosis using this method will detect as little as one organism /test (joss et al., 2008). In our study the results of polymerase chain reaction (PCR) for both negative and positive groups can be very reliable, accurate and dependable to carry out another type of studies such as detection of Bcl-2 and p53.
The present study is the first locally conducted to study Bcl-2 and p53 proteins as parameters that reflect some of the apoptotic process in the trophoblastic tissue from paraffin-embedded samples diagnosed for infection of Toxoplasma gondii using polymerase chain reaction (PCR).

Bcl-2 expression was higher in both negative and control group, in the negative group (mean $34.90 \% \pm 3.44$ ) and induced abortion (mean $38.19 \% \pm 0.79$ ) group which was negative to $T$. gondii, while the lowest percentage (mean 10.93\% \pm 1.44 ) was found in the T. gondii positive group, depending on this results our opinion that Bcl-2 have no role in the abortion process associated with $T$. gondii infection.

There was no statistical difference $(\mathrm{p} \leq 0.363)$ in the mean percentage of Bcl2 between $T$. gondii negative and induced abortion groups, while there was high significance differences $(p=0.000)$ in the mean percentage of $\mathrm{Bcl}-2$ between $T$. gondii positive group and induced abortion group. There was high significance differences $(p=0.000)$ in the mean percentage of $\mathrm{Bcl}-2$ between $T$. gondii positive and negative groups.

Multiple nuclei sharing the same cytoplasm is a morphological characteristic of syncytiotrophoblast. In such cells, the apoptotic signal may be transmitted from one nuclear to another, and cause a spontaneous abortion. Therefore, the number of nuclei undergoing apoptosis in the syncytiotrophoblast should be limited by some mechanism in order to ensure normal embryo development in normal pregnancy. The major role of apoptosisassociated Bcl-2 expression in the syncytiotrophoblast might be to limit the nuclear degradation to a special area and inhibit the spread of cell apoptosis signals to the other nuclei sharing the same cytoplasm, thus sustain cell survival in these multi-nucleated cells (Peng Wei et $a l . ; 2005)$. Our results agreed with the above information and approved that Bcl-2 levels were low in the cases of spontaneous abortion and have no role in preventing of apoptosis in the positive cases for toxoplasma gondii infection. 
The higher percentage level of p53 protein was found in the $T$. gondii positive group $(31.56 \% \pm 1.28)$ and the lowest percentage was in both $T$. gondii negative and induced abortion groups (18.93\% \pm 1.05 and $11.73 \% \pm 1.81)$ respectively. There was statistical difference $(\mathrm{p} \leq 0.003)$ in the mean percent of p53 between $T$. gondii negative and induced abortion group. In addition there was high significance differences $(p=0.000)$ in the mean percent of p53 between $T$. gondii positive group and induced abortion group, and there was a high significance differences $\quad(p=0.000)$ in the mean percentage of $\mathrm{p} 53$ between $T$. gondii positive and negative groups.

Our results agreed with many studies and approved higher levels for p53 protein in the cells of infected women with toxoplasma gondii and this indicate the big and possible role of $\mathrm{p} 53$ protein in the induction of apoptosis and lead to the abortion in those women. Detlef Pietrowski et al. (2005).

In a study of Savion et al. (2002) suggested a role of p53and Bcl-2-mediated apoptosis in pregnancy loss in mice and our current study approved that on human tissues.Imbalances of these highly regulated processes of tissue or cell differentiation caused by an increased number of cells arrested at the G1 checkpoint, might to some extent cause inadequate supply of nutrients, gases or waste exchange between mother and fetus, leading to preterm abortion. A second possible explanation for the observed increase of abortion for $\mathrm{p} 53$ carriers might be their higher potential to resist apoptosis. The lower level of apoptosis in these carriers might lead to misguided growth of cells or tissues determined to be degraded by intrinsic apoptotic stimuli. However, these possible explanations are largely speculative and a more extensive study on how the p53 Pro variant contributes to preterm abortion is required.

Hirofumi Yamauchi et al; 2007 has reported the production of $\mathrm{p} 53$ protein in placentas and recent investigations has shown that more p53 protein is produced by the human placentas in abnormal pregnancies. So in conclusion we can say that, Bcl-2 protein was found in high levels in negative and induced abortion suggesting a role in the normal process of apoptosis that occur in the placenta. And P53 protein found to be at higher levels in the toxoplasma positive group suggesting an important role of this protein in the induction of apoptosis leading to abortion and pregnancy lost.

\section{REFERENCES}

Alfonso, Y.; Fraga, J. and Cox, R. (2008). Comparison of four DNA extraction methods from cerebrospinal fluid for the detection of Toxoplasma gondii by polymerase chain reaction in AIDS patients. Med. Sci. Monit., 14: MT 1-6.

Assmar, M.; Terhovanessian, A. and Fajrak, H. (2000). Detection of Toxoplasma gondii dead fetuses by polymerase chain reaction (PCR). Irn. J. Med. Sci., 25: 59-61.

Detlef Pietrowski, Hertha Bettendorf, EvaKatrin Riener, Christoph Keck1, Lukas A.Hefler, Johannes C.Huber, Clemens Tempfer. (2005).Recurrent pregnancy failure is associated with a polymorphism in the p53 tumour suppressor gene. Human Reproduction, 20(4):848-851.

Dupon, M.; Cazenave, J.; Pellegrin, JL.; Ragnaud, JM.; Cheyrou, A.; Fischer, I.; Leng, B. and Lacut, JY. (1995). Detection of Toxoplasma gondii by PCR and tissue culture in cerebrospinal fluid and blood of human immunodeficiency virusseropositive patients. J. of Clinical Microbiology, 33(9): 2421-2426.

Fabio, A.; Colombo, José E.; Vidal, Augusto C.; Penalva de Oliveira, Adrián V. Hernandez, Francisco Bonasser-Filho, Roberta S. Nogueira, Roberto Focaccia, and Vera Lucia Pereira-Chioccola. Diagnosis of Cerebral Toxoplasmosis in AIDS Patients in Brazil: Importance of Molecular and Immunological Methods Using Peripheral Blood Samples. Journal of Clinical Microbiology, 2005, Vol. 43 (10): 5044-5047.

Fatoohi, A. F.; Cozon, G. J. N. and Greenland, T. (2002). Cellular immune responses to recombinant 
antigens in pregnant women chronically infected with Toxoplasma gondii. Clin. Diag. Lab. Immunol., 9:704-707.

Hirofumi Yamauchi, Kei-ichi Katayama, Masaki Ueno, Xi Jun He, Takashi Mikami, Koji Uetsuka, Kunio Doi, Hiroyuki Nakayama (2007). Essential role of p53 in trophoblastic apoptosis induced in the developing rodent placenta by treatment with a DNA-damaging agent. Apoptosis .12:1743-1754.

Hökelek, M. (2005). Toxoplasmosis. www.e Medicine.com, Inc.

Joss, AWL.; Evans, R.; Mavin, S.; Chatterton, J. and Ho-yen, DO. (2008). Development of realtime PCR to detect Toxoplasma gondii and Borrelia burghorferi infections in postal samples.J.Clin. Pathol. 61:221-224.

Matos, K.; Muccioli, C. and Belfort Junior, R. (2007). Correlation between clinical diagnosis and PCR analysis of serum, aqueous, and vitreous samples in patients with inflammatory eye disease. Arq. Bras. Oftalmol., 70: 109-114.

Nazan Dalgıç, M. D. (2008). Congenital Toxoplasma gondii infection. Marmara Medical. J., 21: 89-101.

Nimri, L.; Pelloux, H. and Elkhatib, L. (2004). Detection of Toxoplasma gondii DNA and specific antibodies in high-risk pregnant women. Am. J. Trop. Med. Hyg., 71: 831-835.

Ordinaire, I.; Simon, A.; Fri@alle, E.; Soula, F.; Valat, A.S.; Rouland, V.; Subtil, D.; Dei-Cas, E.; Camus, D. and Delhaes, L. (2005). Real-time quantitative PCR for toxoplasmosis diagnosisAnn Biol Clin (Paris). JanFeb., 63(1):67-73.
Pashanina, T. P.; Napalkova, G. M. and Korsakova, I. I. (2005). Prevalence of toxoplasmosis and methods for its laboratory diagnosis. Med. Parazitol. (Mosk)., 1: 51-54.

Pelloux, H.; Bessières, M.H. and Chemla, C. (2006). Detection of antitoxoplasma IgM in pregnant women. Ann. Biol. Clin. (Paris), 64: 95.

Peng Wei; Xuan Jin; Xue-Sen Zhang; Zhao-Yuan, $\mathrm{Hu}$; Chun-Sheng, Han. and Yi-Xun, Liu. (2005). Expression of Bcl-2 and p53 at the fetalmaternal interface of rhesus monkey. Reproductive Biology and Endocrinology, 3:4.

Remington, J. S. (2001). Toxoplasmosis in Infectious diseases of the fetus and newborn infant Remington, J. S. and Klein, J. O. (Eds.). $5^{\text {th }}$ ed. W. B. Saunders Company, Philadelphia. pp. 205-346.

Savion, S.; Lepsky, E. and Orenstein, H. (2002). Apoptosis in the uterus of mice with pregnancy loss. Am J Reprod Immunol 47:118-127.cited from Detlef Pietrowski et al., 2005.

World Health Organization (2003). Basic Laboratory Procedures in Clinical Samples, $2^{\text {nd }} E d$.

Yong-beom kim, Jeong-kyu kim, SeungHwa hong, Choong-Hee Won, SeokJae Lee, Chang-Soo Hong, III-Woon Ji, Eun-Hwan Jeong,Hak-Soon Kim. (2001). programmed cell death in placenta; Chungbuk med. J. 11(2):105-116. 


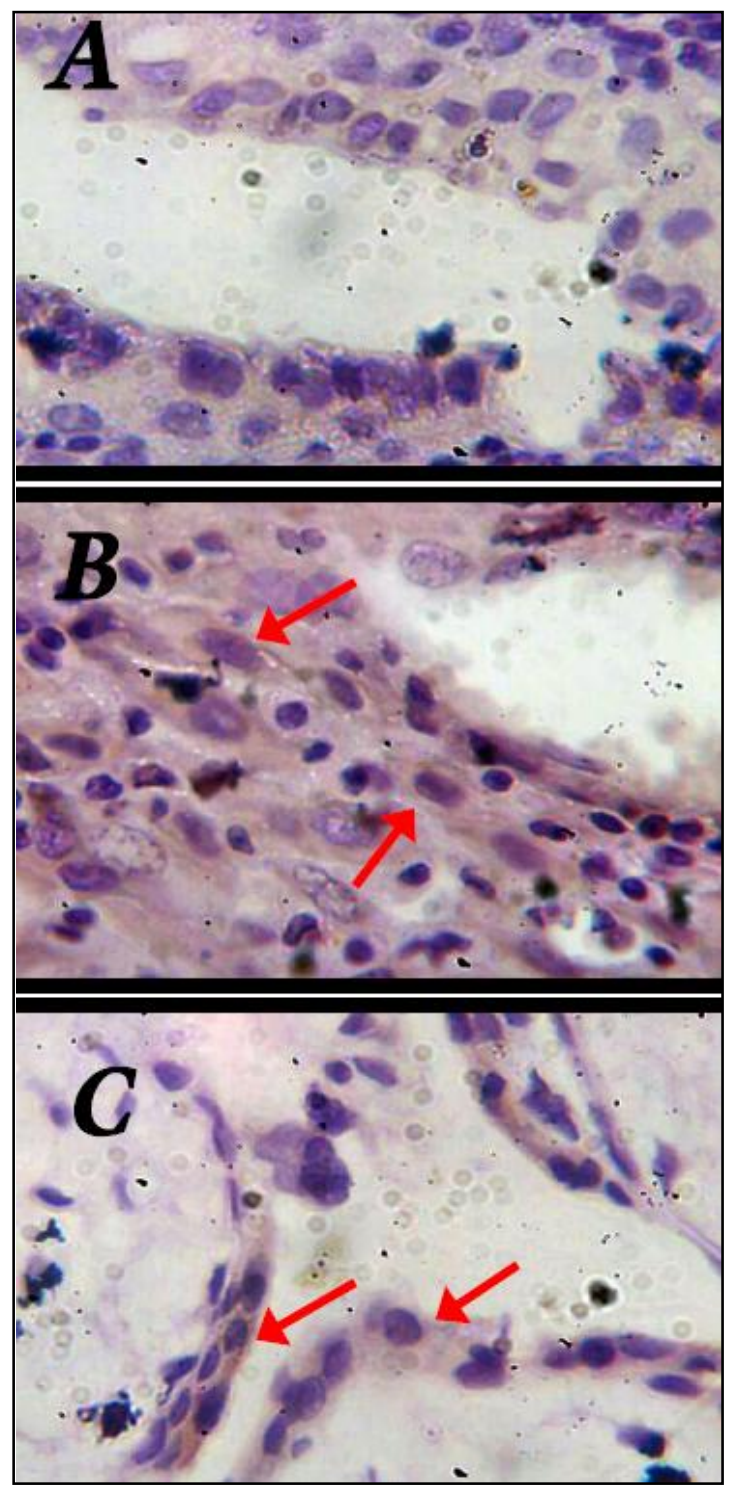

Fig. 4: Immunohistochemical staining (IHC) of Bcl-2 protein in the three groups under study. (A) In Toxoplasma gondii positive group. (B) In Toxoplasma gondii negative group. (C) Induced (control) group. Arrows indicate for positive stain DAB chromogen (dark brown) counterstained with Mayer's Hematoxylin. Magnification (X400).
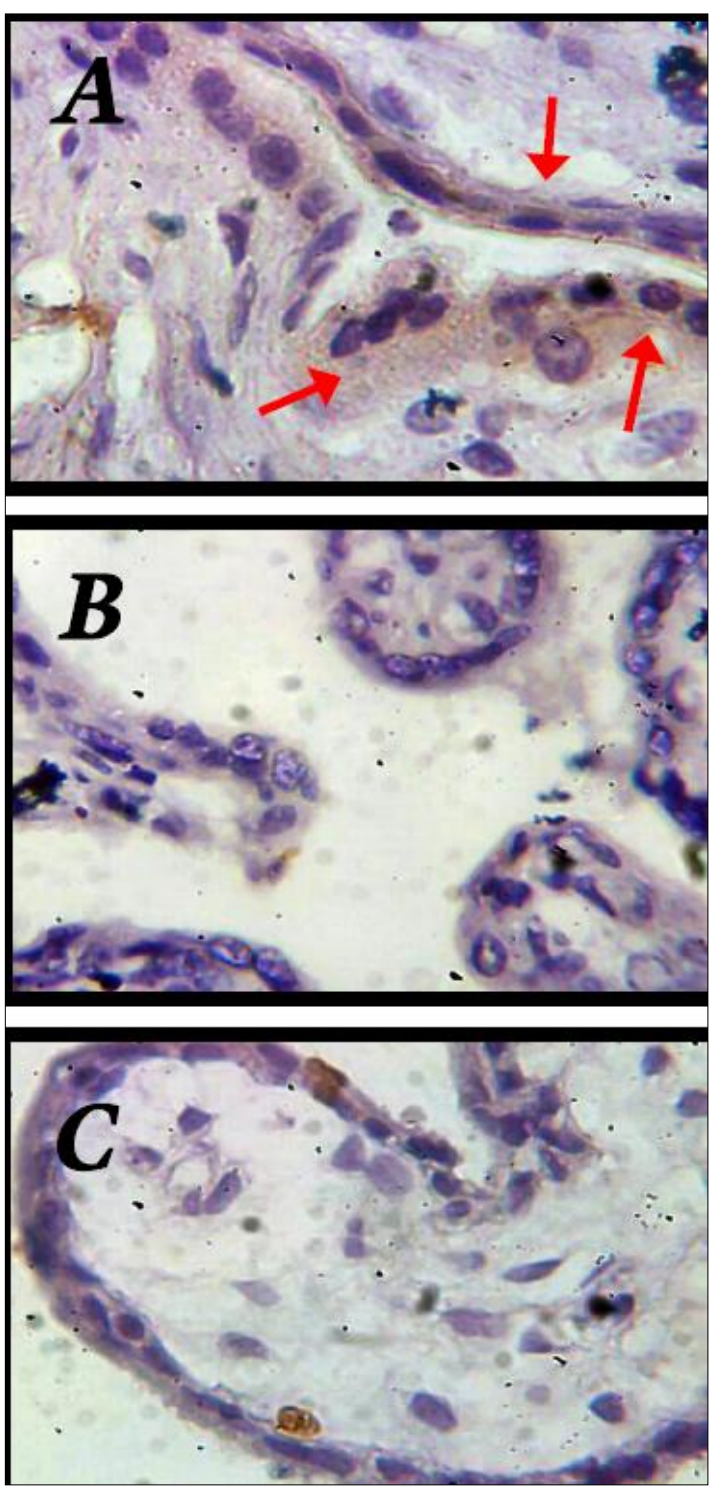

Fig. 5: Immunohistochemical staining (IHC) of p53 protein in the three groups under study. (A) In toxoplasma gondii positive group.(B) in T.gondii negative group, and induced (control) group (C), Arrows indicate for positive stain for Staining by DAB chromogen (dark brown) counterstained with Mayer's Hematoxylin. Magnification (X400) 


\title{
ARABIC SUMMARY
}

\section{تقييم التعبير عن بروتينات الموت الفسلجى فى النسيج المغذى للجنين( التروفوبلاست) لنساءمصابات بلاء

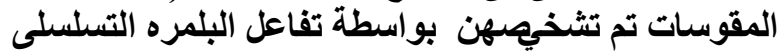

\author{
نضال عبد المهيمن - صفاء مزبان \\ كلية طب النهزين - قسم الاحياء المجهريه
}

\begin{abstract}
طفيلى المقوسات B1 يؤكد مدى خصوصية وحساسية التفاعل التسلسلى البلمري كوسيلة جزيئية لتشخص

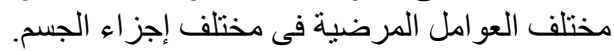

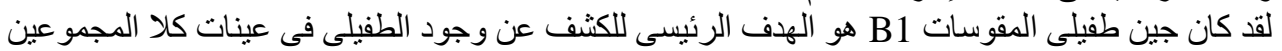

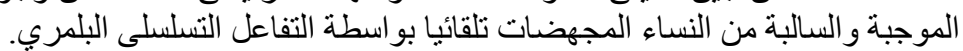

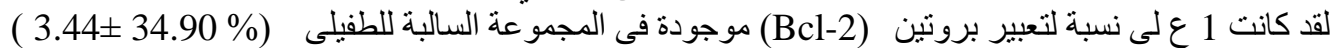

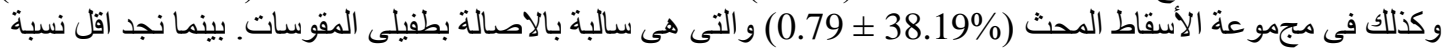

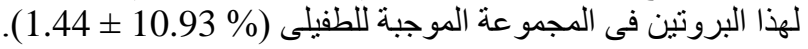

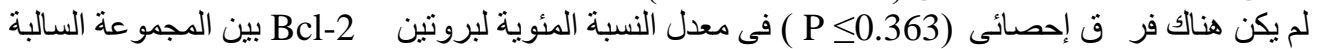

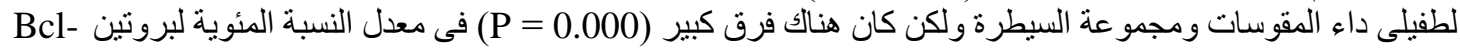

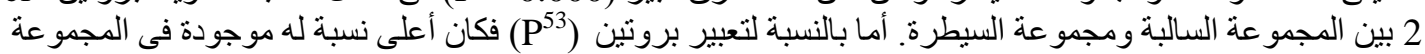

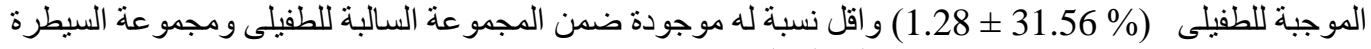
(18.93\%)

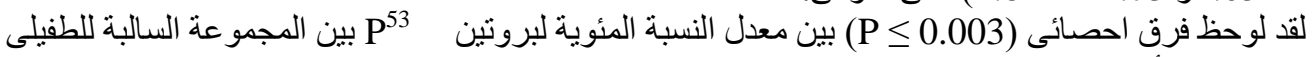

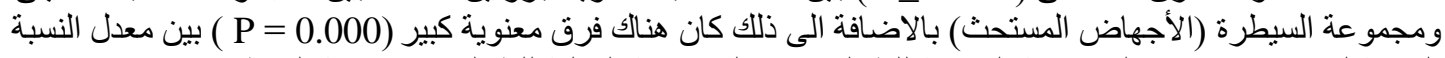

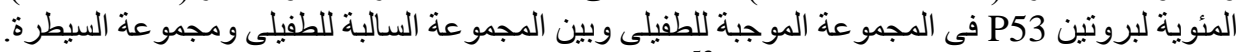

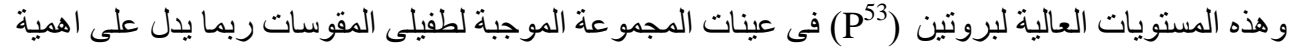

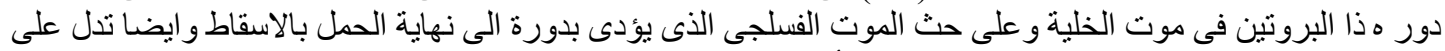

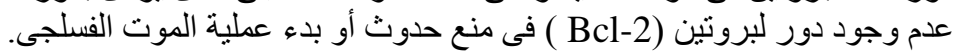

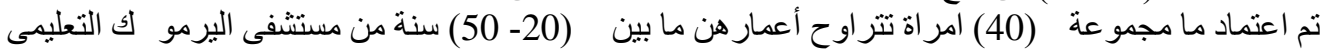

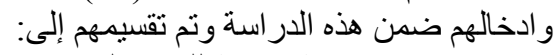

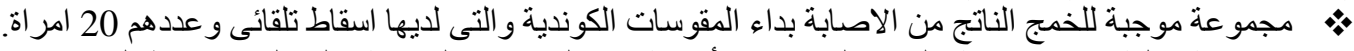

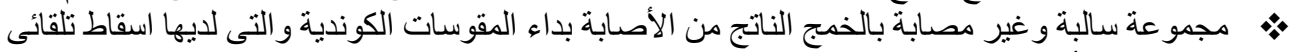
و وعددهم 10 أمر اة.

• مجمو عة السيطرة (نساء ثم عمل اسقاط محث لهم لاسبب طبيا) و عدهم 10 أمر اة.

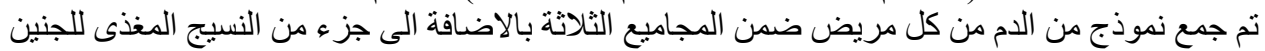

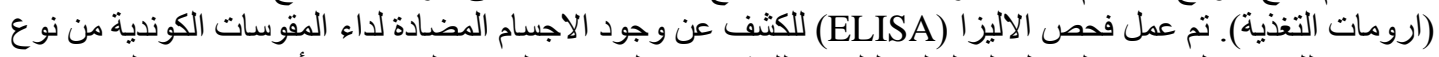

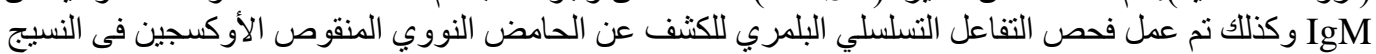

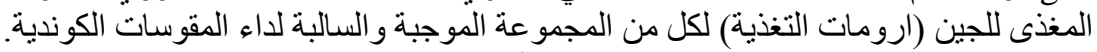

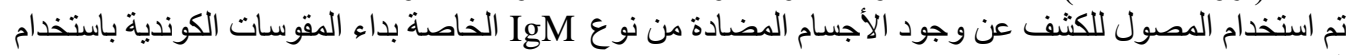

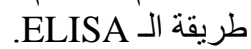

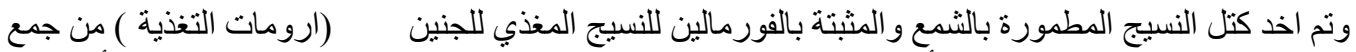

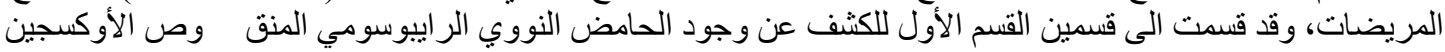

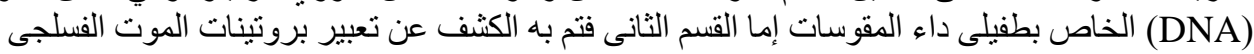
(P53,Bcl-2) لكل من اسطة استعمال التحليل المناعى النسيجى الكيميائي (APOPTOSIS)

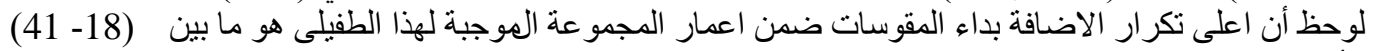

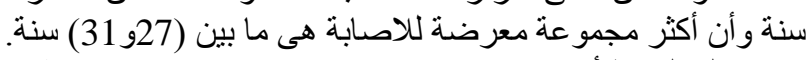

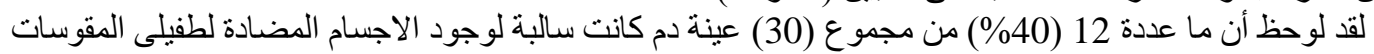

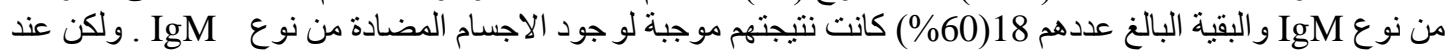

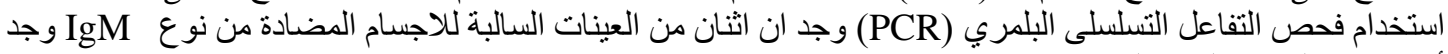

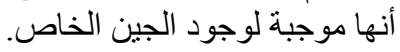

